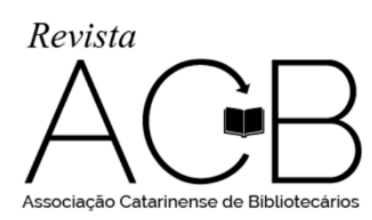

\title{
INOVAÇÃO EM BIBLIOTECAS: RELATO DE EXPERIÊNCIA SOBRE A CRIAÇÃO DO APLICATIVO VESTBOOK SC
}

\author{
Guilherme Martins ${ }^{1}$ \\ Helen Moro de Luca ${ }^{2}$ \\ Janaína dos Santos Schweitzer ${ }^{3}$ \\ Jordan Paulesky Juliani ${ }^{4}$ \\ Divino Ignácio Ribeiro Junior 5
}

\begin{abstract}
Resumo: O trabalho apresenta um relato de experiência sobre oportunidades para o uso de Tecnologias de Informação e Comunicação (TICs), em especial smartphone em bibliotecas públicas. Com o desenvolvimento e o avanço das tecnologias, a comunicação entre as pessoas ficou mais rápida e eficiente, o que facilita a disseminação da informação. A criação de um aplicativo com o objetivo de reunir em um só dispositivo, informações sobre as obras literárias exigidas nos principais vestibulares das Universidades de Santa Catarina. A utilização do aplicativo é benéfica aos usuários das bibliotecas públicas, facilitando o acesso a informações dos livros para vestibulandos.
\end{abstract}

Palavras-chave: Tecnologias de Informação e Comunicação. Aplicativos móveis. Biblioteca Pública. Relato de experiência.

\section{INTRODUÇÃO}

As Tecnologias de Informação e Comunicação (TICs) estão cada vez mais presentes no cotidiano das pessoas na sociedade atual, vive-se em um período dominado pela inovação tecnológica e a mudança nas dinâmicas econômicas, sociais e culturais.

Escrever sobre o uso e aplicação das TICs em bibliotecas atualmente é reportar-se a uma série de experiências exitosas no âmbito da biblioteconomia. Desde a automação das bibliotecas, criação dos catálogos online, mecanismos de recuperação da informação, as TICS apresentam-se como grandes aliadas das bibliotecas, e quando caminham juntas, conseguem alcançar seus objetivos de disseminação da informação.

Dentre essas inovações tecnológicas, que podem ser utilizadas em bibliotecas, os dispositivos móveis apresentam um avanço na forma de se comunicar. Além de realizar e receber chamadas, os celulares

\footnotetext{
1 Mestrando em Gestão de Unidades de Informação na Universidade do Estado de Santa Catarina (UDESC). E-mail: gm.biblio@gmail.com

${ }^{2}$ Mestranda em Gestão de Unidades de Informação na Universidade do Estado de Santa Catarina (UDESC). E-mail: helen.mdeluca@gmail.com

3 Mestranda em Gestão de Unidades de Informação na Universidade do Estado de Santa Catarina (UDESC). E-mail: janaedino@gmail.com

4 Doutor em Engenharia e Gestão do Conhecimento - Universidade Federal de Santa Catarina (UFSC). E-mail: jordan@webpack.com.br

5 Doutor em Engenharia e Gestão do Conhecimento - Universidade Federal de Santa Catarina (UFSC). E-mail: divinoirj@gmail.com
} 


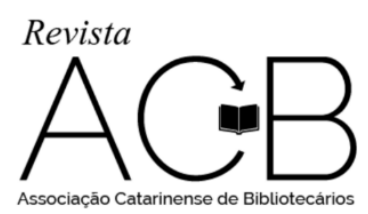

Revista ACB: Biblioteconomia em Santa Catarina, Florianópolis, v. 22, n. 3, p. 596-610, ago./nov., 2017.

smartphones englobam algumas das principais tecnologias de comunicação em somente um dispositivo: internet, GPS, e-mail, SMS, redes sociais e aplicativos para muitos fins. Diante de uma gama de funcionalidades, os celulares smartphones não saem das mãos das pessoas. Dados da Anatel indicam que o Brasil terminou outubro de 2016, com 247,5 milhões de celulares e densidade de 119,84 celulares para cada 100 habitantes (TELECO, 2016).

A partir da vivência diária dos autores (atuantes em biblioteca pública e biblioteca escolar de Santa Catarina), constatou-se que os usuários destas instituições têm mais facilidade e afinidade com aparelhos smartphone, pela facilidade de compra e preço mais reduzido, em face de um computador pessoal, utilizando-o para comunicação e acesso às redes sociais, no qual, usam a internet sem fio ou a internet móvel da própria operadora de telefonia.

Nesses tipos de bibliotecas existe uma grande procura por livros de literatura em geral, mas é perceptível a busca pelos livros indicados para os vestibulares das Universidades de Santa Catarina.

O vestibulando além da leitura integral das obras, procura por outros tipos de detalhes a respeito dos textos, como por exemplo: estilo literário; narrativa; biografia do autor; formas de aquisição da obra; domínio público. É possível encontrar inúmeras informações sobre elas na internet, porém de forma fragmentada, o que acaba por exigir do vestibulando, uma pesquisa exaustiva nos principais motores de busca da web.

A sociedade atual possui alta dependência de acesso à internet para obter os serviços e as informações que necessita. Para Castillo Goméz (2004), a sociedade está imersa na cultura audiovisual e envolta pela cultura escrita. E diante disso, a cultura escrita teve que se adaptar aos novos modos de agir, vindos com a nova geração: a leitura escrita por dispositivos tecnológicos. É possível encontrar livros editados física e eletronicamente, assim como resumos, interpretações de textos, vídeos sobre o tema do livro, entre outros.

Partindo dos pontos apresentados questiona-se: de que forma as bibliotecas públicas podem contribuir para a disseminação das informações referentes às obras literárias para vestibular das Universidades de Santa Catarina?

Com esses pressupostos, buscou-se criar um protótipo de aplicativo capaz de reunir em um único dispositivo, informações referentes às obras literárias exigidas nos vestibulares das Universidades de Santa Catarina, unindo o papel de disseminação da informação das bibliotecas públicas, com os aplicativos de dispositivos móveis das TICS. A criação deste aplicativo aliado a vasta utilização de smartphones, poderá proporcionar aos usuários acesso às informações que lhe são interessantes, sobre os livros do vestibular. 


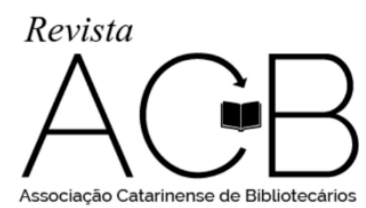

Revista ACB: Biblioteconomia em Santa Catarina, Florianópolis, v. 22, n. 3, p. 596-610, ago./nov., 2017.

No mercado comercial para smartphones não foram observados, aplicativos voltados para obras literárias consideradas obrigatórias para os vestibulares de Universidades brasileiras. Sendo assim, justificase a criação de um protótipo de aplicativo para dispositivo móvel, que tenha como público-alvo os vestibulandos, que buscam informações sobre as obras literárias para os vestibulares de Santa Catarina. Este protótipo de aplicativo móvel passou a ser denominado Vestbook SC. Importa ressaltar, que este artigo é um relato de experiência, no qual são elencados os procedimentos adotados na criação do aplicativo para dispositivos móveis.

O Vestbook SC além de apresentar informações importantes sobre as obras do vestibular, poderá auxiliar seus usuários na capacidade de análise e interpretação dos textos integrais. Segundo os portais da UFSC e da UDESC, para a realização das provas, é importante compreender o contexto histórico, social, cultural e estético de cada livro.

Este aplicativo foi desenvolvido empiricamente por três bibliotecários, que perceberam a necessidade de facilitar o acesso à informação, em bibliotecas públicas e escolares. Desta forma, a apropriação das tecnologias pelo profissional da informação mostrou-se fundamental na nova dimensão da sociedade da informação. Compete, também, a estes profissionais, a busca por soluções tecnológicas que insiram, cada vez mais, o usuário das bibliotecas no mundo das TICs, além de traçarem um novo perfil para a profissão. Para Silva (2014),

[...] as tecnologias de informação e comunicação (TIC) exigem um novo perfil de profissional. É preciso que o bibliotecário domine o uso do computador, compreenda e saiba utilizar a rede mundial de computadores (www), onde encontrar e filtrar a informação e como disponibilizá-la e levá-la ao usuário certo.

O aplicativo Vestbook $S C$ foi criado para auxiliar os estudos dos vestibulandos em um período de muita ansiedade. $\mathrm{O}$ aplicativo não tem a intenção de substituir a leitura integral das obras, mas sim tornar-se um material de apoio, para a total compreensão das obras, visando transpor as barreiras que podem impedir que os usuários tenham acesso à informação e a construção do conhecimento.

\section{USO DE TICS EM BIBLIOTECAS}

A incorporação das novas tecnologias em ambientes tradicionais, como as bibliotecas, tem se mostrado altamente eficaz do ponto de vista da satisfação do usuário. A partir da utilização destas 


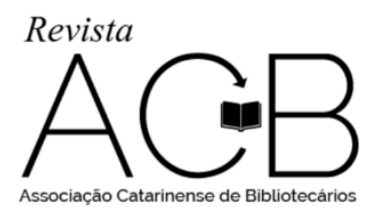

Revista ACB: Biblioteconomia em Santa Catarina, Florianópolis, v. 22, n. 3, p. 596-610, ago./nov., 2017.

inovações, eles interagem com o ambiente, e têm a possibilidade de realizar tarefas, relacionadas aos serviços da biblioteca, de maneira remota otimizando seu tempo.

Segundo Souza, Torres e Amaral (2011), “tecnologias são artefatos criados para facilitar a existência humana, sendo fruto da apropriação e do uso que damos às coisas que permeiam nossa vida material. Tecnologias são, também, fruto de um processo social”, por isso a importância cada vez maior do uso e apropriação das TICs, por parte dos profissionais da informação e dos usuários de seus serviços, que cada vez mais ditam as dinâmicas tanto no contexto tecnológico quanto o social.

As TICs concedem segundo Souza, Torres e Amaral (2011), aos seus usuários, uma melhor apreensão de informações, geram conhecimento, ampliam conceitos, transformam experiências, completam os saberes e auxiliam no saber-fazer, com eficiência. As tecnologias móveis são um exemplo de TICs, e elas possuem grande potencial transformador no cotidiano das pessoas.

Em bibliotecas, o uso das tecnologias torna-se imprescindível para que o usuário entenda a potencialidade daquele ambiente e dos serviços que são oferecidos por elas. De acordo com Silva (2004),

[...] as bibliotecas tiveram seu perfil alterado com as TICs. As tecnologias permitiram melhorias nos serviços prestados, estas contribuíram para que novos usuários fossem atraídos possibilitando assim que a informação atinja cada vez mais um número maior de pessoas. Possibilitando também uma interação direta e mais rápida com os usuários os tornando de certa forma independentes na busca por informações.

Os usuários de bibliotecas também foram adaptados pelas TICS, de acordo com Griebler e Mattos (2007), os usuários de biblioteca se auto atendem, pois, as informações podem ser acessadas de casa e na rua, sendo assim, a biblioteca de certa forma, passou a atender vinte quatro horas por dia. Esta nova possibilidade de relacionamento entre biblioteca e usuário, possibilita a geração de novos serviços, que atendam as necessidades da comunidade na qual estão inseridos.

As TICs exigem um novo perfil de profissional, é preciso que o bibliotecário compreenda as TICs para assimilar os novos desafios das tecnologias e aliá-las a seu cotidiano (SILVA, 2014). Quando o bibliotecário possui conhecimento acerca das novas tecnologias, ele pode incorporá-las às suas práticas de trabalho, buscando facilitar o processo de disseminação da informação de forma oportuna.

A biblioteca pública, como conceito e diretriz, está baseada na igualdade de acesso, sem restrições a credo, raça ou status social. Tem como objetivo oferecer todo e qualquer tipo de material que seja interessante para a comunidade na qual está inserida. A biblioteca pública tem o papel de mediadora entre a sociedade e o governo, além de disponibilizar as informações de maneira organizada e padronizada (BRASIL, 2010). 


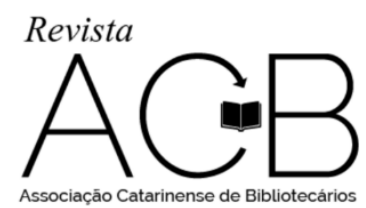

Revista ACB: Biblioteconomia em Santa Catarina, Florianópolis, v. 22, n. 3, p. 596-610, ago./nov., 2017.

Voelcker (2013), afirma que

[...] as bibliotecas públicas, embora com pouca expressão quantitativa entre os pontos públicos de acesso à tecnologia, são tomadas como potenciais organizações para a construção de estratégias de uso da Internet para o desenvolvimento socioeconômico no Brasil.

As políticas públicas ofertadas no Brasil, juntamente com os incentivos nas próprias bibliotecas, recaem somente sobre a promoção e o incentivo à leitura, basicamente para o público infantil. Para os jovens e adultos, o espaço da biblioteca é utilizado apenas como local de estudo. Cabe ressaltar que, o uso de tecnologias e o acesso à internet são grandes chamarizes para este público que está sempre conectado às redes sociais e aos canais de comunicação. Voelcker (2013, p.5), conclui que "a oferta de acesso à tecnologia atrai muitos usuários, mas estes constituem um grupo à parte das demais ações da biblioteca".

Com a missão de dar acesso à informação e democratizar o espaço das unidades de informação, as bibliotecas públicas podem constituir instrumentos tecnológicos que facilitem a interação de seus usuários com a instituição, e principalmente o interesse destes usuários para com a biblioteca. A partir desta ação, a biblioteca passaria a ser vista de modo diferente pelos jovens e adultos, usuários potenciais, os quais têm acesso a todo tipo de informação, por meio da internet, com apenas um clique ou toque.

\section{APLICATIVOS MÓVEIS}

Um aplicativo móvel, conhecido normalmente por seu nome abreviado app, é um software desenvolvido para ser instalado em um dispositivo eletrônico móvel, como um telefone celular smartphone. Este aplicativo pode ser instalado no dispositivo, sendo baixado pelo usuário por meio de uma loja on-line, como a Google Play, Apple Store ou Windows Phone Store.

Uma parte dos aplicativos disponíveis é gratuita, enquanto outros são pagos. Estes aplicativos são pré-instalados ou são nativos do telefone (vêm direto da fábrica), e podem ser baixados pelos clientes de várias plataformas de distribuição de software móvel ou aplicativos da web.

Meirelles (2016) cita que, na $27^{\mathrm{a}}$ edição da Pesquisa Anual de Administração e Uso de Tecnologia da Informação nas Empresas realizada pela Fundação Getúlio Vargas de São Paulo (FGV-SP) mostra que, o Brasil chegou a 168 milhões de smartphones em uso, um crescimento de $9 \%$ em relação ao levantamento de 2015. De acordo com o estudo, a expectativa é de que, nos próximos dois anos, o País tenha 236 milhões de aparelhos desse tipo nas mãos dos consumidores, em um crescimento de $40 \% \mathrm{em}$ relação ao momento atual. 


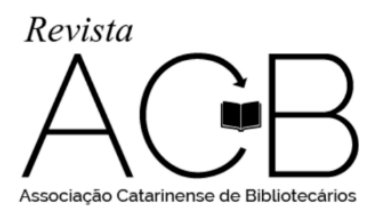

Revista ACB: Biblioteconomia em Santa Catarina, Florianópolis, v. 22, n. 3, p. 596-610, ago./nov., 2017.

Os dados apontam uma tendência global, para o uso cada vez maior de smartphones, o que consequentemente criará uma oferta cada vez maior de aplicativos para esses dispositivos disponíveis no mercado buscando facilitar serviços e otimizar o tempo dos usuários.

\section{CONCEITO DE PROTÓTIPO}

A palavra protótipo é derivada do grego, onde (Protós), significa primeiro e (Typos), significa tipo; mas uma tradução mais correta, seria: primeiro modelo, que está em fase de testes, estudo ou planejamento (GRANDO, 2013). Protótipos, em linhas gerais, podem ser entendidos como modelos funcionais construídos a partir de especificações preliminares para simular a aparência e a funcionalidade de um software a ser desenvolvido, ainda que de forma incompleta.

Rubin (1994) afirma que ao desenvolver um protótipo não se faz necessário representar toda a funcionalidade do produto. Pelo contrário, somente deve ser apresentada a funcionalidade que atenda aos objetivos do teste ou da avaliação. Quando se quer, por exemplo, conhecer a reação do usuário sobre uma organização de categorias, somente será necessário apresentar o menu com uma camada de opções. Devese projetar a página inicial, com todas as chamadas principais, e certificar-se de que cada link se conecta com pelo menos uma página. Dessa forma pode-se testar o nível de compreensão das categorias principais.

Com o objetivo de identificar necessidades e oportunidades para o uso das tecnologias da informação e comunicação (TICs) nas bibliotecas públicas e escolares brasileiras, este relato visa apresentar a experiência de elaboração de um protótipo de aplicativo móvel, com informações sobre os livros indicados para os vestibulares das Universidades de Santa Catarina.

\section{RELATO DE EXPERIÊNCIA}

Os procedimentos adotados para o desenvolvimento do aplicativo Vestbook SC, foram: pesquisa bibliográfica para constituir o aporte teórico do tema proposto, efetuando-se consultas às bases do Portal CAPES, Scielo e à Biblioteca Digital Brasileira de Teses e Dissertações; definição do escopo do aplicativo; pesquisa sobre vestibular, nos documentos eletrônicos disponíveis nos portais das Universidades de Santa Catarina. Além disso, foi realizado um estudo das tecnologias disponíveis que promovessem a criação de aplicativos gratuitamente. Dentre as opções estudadas, optou-se pela versão gratuita disponibilizada pela plataforma on-line AppMachine que viabiliza a criação e o compartilhamento de aplicativos para celulares. 


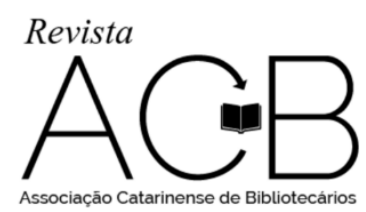

Revista ACB: Biblioteconomia em Santa Catarina, Florianópolis, v. 22, n. 3, p. 596-610, ago./nov., 2017.

O processo de criação do aplicativo iniciou-se com uma ideia de tema e após debate sobre a real necessidade de criação de tal aplicativo, a equipe fez um apanhado na internet, de ferramentas para criação de aplicativos on-line e gratuitos, por meio do buscador Google.

Com a recuperação de inúmeras sugestões, a equipe selecionou, utilizando-se do critério de melhor pontuação das plataformas em sites especializados em tecnologia, duas opções: a Fábrica de Aplicativos e o AppMachine.

$\mathrm{Na}$ tentativa de criação do Vestbook SC na plataforma on-line Fábrica de Aplicativos, a equipe não alcançou o objetivo esperado por limitações de funcionalidades no plano gratuito e pela plataforma apresentar um layout simples, em relação as suas funcionalidades desejadas

A plataforma on-line AppMachine, atendeu aos objetivos esperados no quesito funcionalidades do plano gratuito, dando maior flexibilidade na criação do aplicativo. Desta forma, o protótipo do aplicativo Vestbook SC foi construído por meio da plataforma para criação de aplicativos móveis, AppMachine.

\subsection{Plataforma AppMachine}

O AppMachine é um software de produção de aplicativos para dispositivos móveis. Utilizando a plataforma on-line foi possível criar o aplicativo Vestbook SC escolhendo o desenho do app, assim como os botões, cores e as funcionalidades gerais.

A plataforma divide estes itens em blocos de montar, nos quais é possível definir as principais finalidades do aplicativo. O trabalho consiste em três fases: design, teste e publicação. O sistema do AppMachine é todo baseado em blocos de LEGO. São 20 blocos básicos que contemplam ferramentas específicas e com possibilidade de personalização. Arrastando os blocos, o cliente modifica o posicionamento do menu, por exemplo.

Durante a criação do app há um sistema de observação prévia para testar as funções por meio de uma tela de smartphone. Também é possível baixar um app preview da própria plataforma, no qual o cliente pode acessar remotamente de seu smartphone o aplicativo, já no formato final.

A criação do aplicativo é grátis, porém se o cliente demonstrar interesse em publicá-lo, passará a ser cobrada uma mensalidade, que varia de acordo com o plano escolhido. No caso do protótipo Vestbook $S C$, o plano escolhido foi o gratuito, portanto o aplicativo não está disponível para download. 


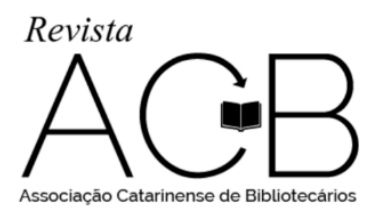

Revista ACB: Biblioteconomia em Santa Catarina, Florianópolis, v. 22, n. 3, p. 596-610, ago./nov., 2017.

\section{RESULTADOS: O APP VESTBOOK SC}

Com o emprego das TICs foi possível a criação de um aplicativo para usuários de bibliotecas, a fim de aprimorar os serviços de disseminação de informação de fácil acesso, constituindo assim um serviço de qualidade viável, a ser executado dentro das bibliotecas públicas.

A partir da escolha da plataforma para a criação do Vestbook $S C$, foi desenvolvido um protótipo do aplicativo que tem por objetivo, auxiliar os vestibulandos que buscam informações sobre os livros de leitura obrigatória para os vestibulares das Universidades de Santa Catarina. Os vestibulares contemplados foram: UFSC, UDESC, IFSC e ACAFE.

Por meio do aplicativo é possível acessar:

- informações sobre o livro (resumo, narrativa, personagens);

- onde encontrar (bibliotecas, livrarias, sebos);

- informações sobre os autores (biografias; outras obras);

- estilo (gênero, período);

- vídeos, links e comentários.

O aplicativo, depois de desenvolvido com o emprego das tecnologias do AppMachine, funciona no modo de cliques para a abertura de telas. Após selecionar a universidade do vestibular desejado o usuário poderá ter informações referentes aos livros do vestibular, assim como: onde encontrar as obras, links úteis sobre o vestibular e também poderá sincronizar o Vestbook $S C$ com sua agenda para ficar atento às datas importantes do vestibular.

Quando selecionada a aba "livros", estarão à disposição do usuário, informações importantes para a total compreensão das obras do vestibular, auxiliando assim na compreensão do contexto histórico, social, cultural e estético de cada livro.

Em relação à localização, é utilizado o sistema de ponto de interesse ou POI (Point of Interest), que marca em um mapa localizações importantes e específicas. No caso do Vestbook SC, são apresentados os locais onde as obras do vestibular podem ser encontradas (para empréstimo ou aquisição) em sua cidade, bairro, estado ou país.

Os links úteis (páginas dos vestibulares) e vídeos do YouTube, são utilizados por meio de endereços que remetem às próprias páginas da internet. No caso de livros que possuem acesso completo via Portal de Domínio Público, é possível também fazer acesso via aplicativo a partir do link.

O usuário ainda pode sincronizar sua agenda do celular, para não perder nenhuma data referente a nenhum dos eventos relacionados ao vestibular, facilitando assim a sua organização. 


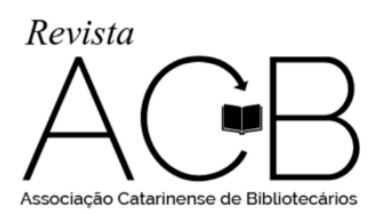

Revista ACB: Biblioteconomia em Santa Catarina, Florianópolis, v. 22, n. 3, p. 596-610, ago./nov., 2017.

O aplicativo Vestbook SC é de fácil entendimento e totalmente intuitivo, funcionando com um sistema de cliques, onde cada aba selecionada leva a outra tela ou opção de menu, até chegar a informação desejada, de forma simples e rápida.

Além das funções do Vestbook SC expostas no protótipo e descritas neste relato de experiência, o Appmachine apresenta ainda, uma série de funcionalidades que podem vir a contribuir muito para o contínuo desenvolvimento do aplicativo, como por exemplo: Perguntas Frequentes ou FAQ (Frequently Asked Question), formulários, e demais elementos que direcionam também as bibliotecas e seus serviços auxiliando os usuários.

A seguir serão apresentadas as principais telas e funcionalidades que compõem o aplicativo Vestbook SC. Na figura 1, é apresentada a tela inicial do aplicativo, onde o usuário seleciona a universidade que prestará vestibular e acessa informações sobre as obras de literatura:

Figura 1 - Tela inicial do aplicativo Vestbook $S C$

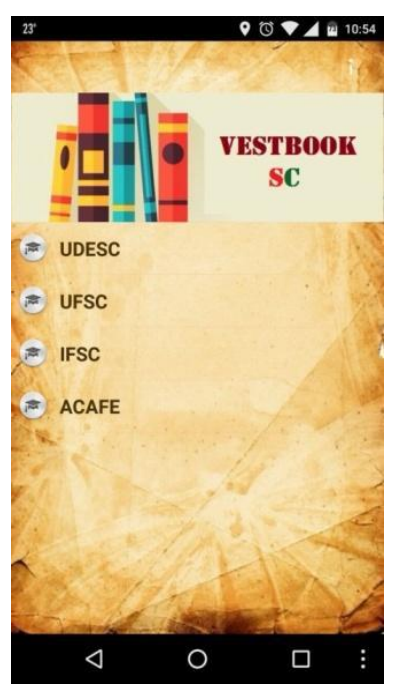

Fonte: Aplicativo Vestbook SC, 2017.

Ao selecionar a opção "Udesc" o aplicativo exibirá todas as informações referentes às obras literárias para o vestibular da Udesc (figura 2). Nesta tela poderão ser executadas as seguintes opções:

- Livros: o aplicativo apresentará a tela com todas as obras de literatura referentes ao vestibular da Udesc;

- Onde encontrar: pontos de localização dos livros em bibliotecas, livrarias e sebos;

- Links úteis:o aplicativo apresentará a página oficial do concurso vestibular;

- Agenda: contempla as datas de realização das provas. 
Figura 2: Opção Udesc

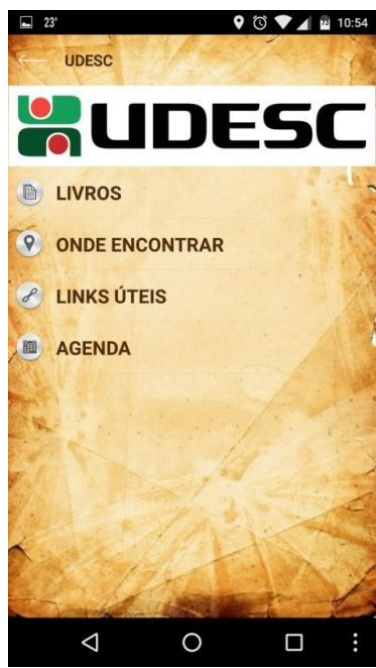

Fonte: Aplicativo Vestbook SC, 2017

Considerando que o usuário optou pelo ícone de Livros na tela anterior, a figura 3 mostra todas as obras de literatura referentes ao vestibular da Udesc:

Figura 3: Opção Livros

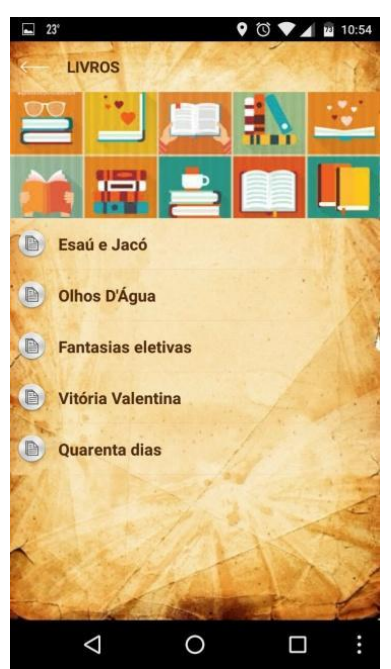

Fonte: Aplicativo Vestbook SC, 2017

Assim que o usuário do aplicativo selecionar uma das obras, aparecerá a tela (figura 4), com todos os detalhes e informações referentes àquele livro: 
Figuras 4: Opção Esaú e Jacó

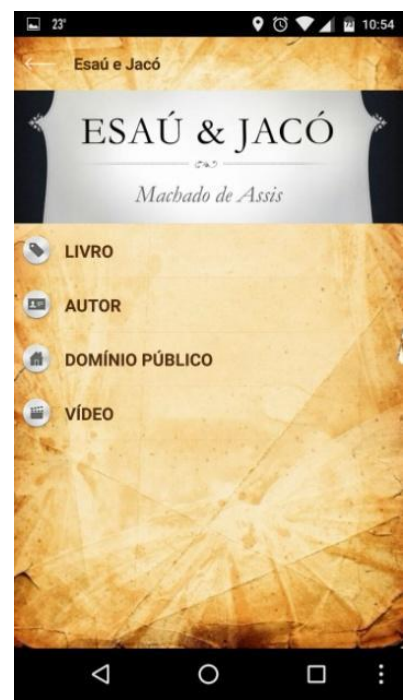

Fonte: Aplicativo Vestbook SC, 2017

Ao retornar ao menu Udesc, o usuário encontra outros submenus como links úteis, no qual aparece a página oficial do concurso vestibular (figura 5).

Figura 5: Links úteis

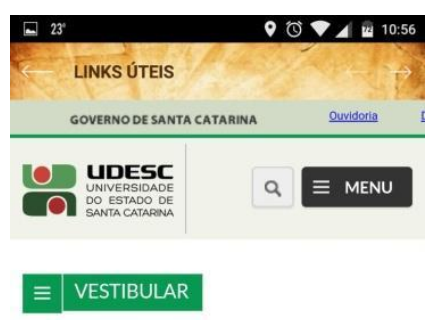

Saiba como funciona

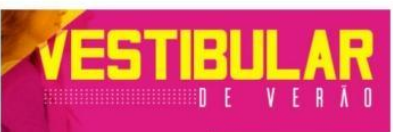

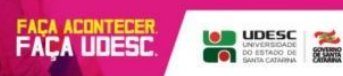

A Udesc oferece mais de 50 cursos de graduaçåo gratuitos

$\triangleleft \quad \bigcirc \quad \square \quad \vdots$

Fonte: Aplicativo Vestbook SC, 2017

Opção onde encontrar, com pontos de localização dos livros em bibliotecas, livrarias e sebos (figura 6): 
Figura 6: Onde encontrar

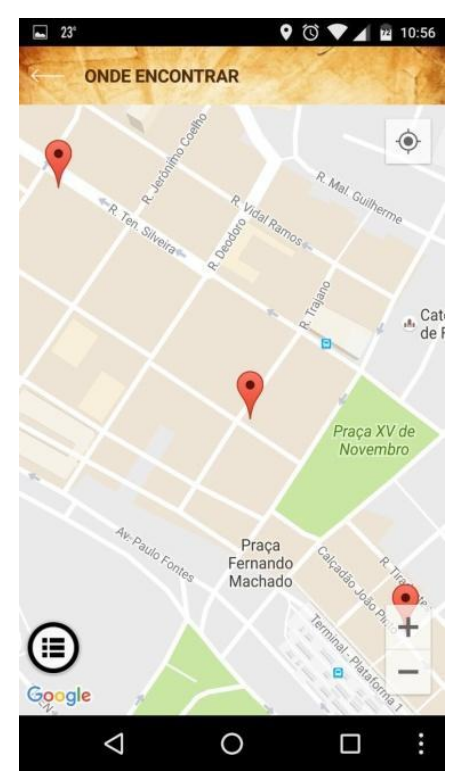

Fonte: Aplicativo Vestbook SC, 2017

O aplicativo funciona de forma totalmente intuitiva, como a maioria dos aplicativos atualmente, valorizando assim a autonomia do usuário, não sendo necessário mediação, ficando o usuário apto a localizar as informações referentes aos livros dos vestibulares de Santa Catarina de seu interesse.

A implementação do aplicativo seria ideal em todas as bibliotecas públicas sinalizando assim uma nova forma de se pensar as bibliotecas públicas no cenário brasileiro.

\section{CONSIDERAÇÕES FINAIS}

Este relato de experiência em bibliotecas públicas e escolares, pode servir de inspiração para outras equipes de bibliotecários e demais profissionais relacionados às instituições, para que possam criar seus próprios aplicativos, relacionados a seus produtos e serviços, prezando o interesse e a demanda dos usuários das bibliotecas.

Muitas vezes a noção de desenvolvimento de aplicativos ou serviços que envolvam TICs, pode ser vista com dificuldade ou obstáculo por bibliotecários, por acreditarem não ter o total domínio das tecnologias e todas suas especificidades. O relato de experiência destacado neste artigo apresenta uma visão diferente da aplicação de TICs, com fácil acesso e uso para usuários de bibliotecas, e bibliotecários como desenvolvedores de um serviço de auxílio. 


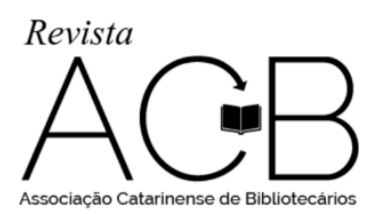

Revista ACB: Biblioteconomia em Santa Catarina, Florianópolis, v. 22, n. 3, p. 596-610, ago./nov., 2017.

As bibliotecas públicas têm por objetivo a disseminação da informação e atendimento aos usuários. As demandas podem ser atendidas de inúmeras formas, e uma delas pode ser o emprego de TICs nos serviços das bibliotecas, que venham a auxiliar na otimização dos serviços. Os aplicativos para dispositivos móveis são grandes aliados na prestação de serviços personalizados, tendo em vista as facetas de cada público e serviço, podendo ser utilizados em bibliotecas.

Eventualmente o aplicativo pode se tornar uma realidade nas instituições, porém é preciso atentar para a atualização das informações, observando que as obras do vestibular mudam todo ano, a confiabilidade das informações disponibilizadas pelo aplicativo e questões relacionadas aos direitos autorais e fonte das informações disponibilizadas, buscando assim realizar um trabalho de disseminação da informação de forma confiável, segura e legalmente correta.

Vale ressaltar, que o aplicativo Vestbook SC não substitui a leitura integral das obras, necessária para total compreensão da narrativa. O aplicativo tem por objetivo ser um assistente no momento dos estudos, reunindo as principais informações sobre as obras.

Este relato de experiência apresenta um potencial de mudança na visão de nossas bibliotecas públicas brasileiras, aproximando os milhares de vestibulandos todos os anos com a leitura e a informação em um formato acessível e de forma independente, mudando a relação e visão dos mesmos referente a nossas bibliotecas públicas.

Aplicativos para dispositivos móveis são uma realidade nos dias de hoje, e grande parte da população está optando pelo uso de aplicativos para: informação, lazer, entretenimento e demais saberes, que irão facilitar o cotidiano das pessoas.

Devido ao crescente desenvolvimento das TICs, a biblioteca pública não é mais a única fonte gratuita de informação. Dessa forma, o papel de acesso à informação desempenhado por esta instituição passa a competir com opções mais práticas e cômodas.

No entanto, esse desenvolvimento tecnológico gera uma infinidade de informação, o que muitas vezes dificulta o acesso eficaz da informação pelo usuário. Assim sendo, a biblioteca pública alinhada às novas TICs, pode inovar seus serviços facilitando o acesso a informação, buscando a aproximação dos seus usuários e seus produtos e serviços.

Esses serviços vêm ao encontro do novo papel da biblioteca pública na sociedade e vários outros podem ser criados, cumprindo o objetivo de satisfazer as necessidades informacionais dos cidadãos. 


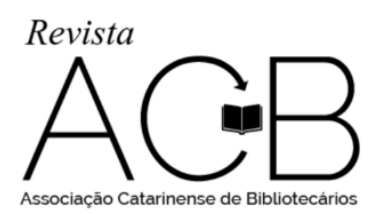

Revista ACB: Biblioteconomia em Santa Catarina, Florianópolis, v. 22, n. 3, p. 596-610, ago./nov., 2017.

\section{REFERÊNCIAS}

BRASIL. BIBLIOTECA PÚBLICA: princípios e diretrizes. Rio de Janeiro: Fundação Biblioteca Nacional, 2010. 160p. (Documentos técnicos ; 6).

CASTILLO GÓMEZ, Antonio. Leer y Escribir en la era de internet: problemas y desafios de la cultura escrita. Revista Educação e Realidade. n. 29(2), jul/dez 2004. p. 41-53.

GRANDO, N. Usando protótipos para dar forma às ideias. Disponível em:

https://neigrando.wordpress.com/2013/06/04/usando-prototipos-para-dar-forma-as-ideias . Acesso em 14 dez. 2016.

GRIEBLER, A. C. de F.; MATTOS, A. M. Novas tecnologias, novas mídias, velhas dificuldades: aprimorando a interface com o usuário para a escolha de base de dados ou periódicos. Encontros Bibli: Revista Eletrônica de Biblioteconomia e Ciência da Informação, n. 23, $1^{\circ}$ sem. 2007. Disponível em: https://periodicos.ufsc.br/index.php/eb/article/view/1518-2924.2007v12n23p73. Acesso em: $06 \mathrm{dez}$. 2016.

MEIRELLES, Fernando S. 27. Pesquisa Anual de Administração e Uso de Tecnologia da Informação nas Empresas. São Paulo: FGV, 2016. Disponível em: http://eaesp.fgvsp.br/sites/eaesp.fgvsp.br/files/pesti2016gvciappt.pdf. Acesso em: 07 dez. 2016.

RUBIN, J. Handbook of Usability Testing: how to plan, design and conduct effective tests. New York: John Wiley\& Sons, 1994.

SILVA, N. R. O bibliotecário mediante as novas tecnologias da informação e comunicação. In: ENCONTRO REGIONAL DE ESTUDANTES DE BIBLIOTECONOMIA, DOCUMENTAÇÃO, CIÊNCIA E GESTÃO DA INFORMAÇÃO, 2014, Fortaleza. Anais... Fortaleza: UFC, 2014. p. 1-15. Disponível em: http://www.erebdfortaleza2014.ufc.br/gt/GT3/O\%20BIBLIOTEC\%C3\%81RIO\%20MEDIANTE\%20AS \%20NOVAS\%20TECNOLOGIAS\%20DA\%20INFORMA\%C3\%87\%C3\%830\%20E\%20COMUNICA \%C3\%87\%C3\%830.pdf . Acesso em: 10 dez. 2016.

SOUZA, M. I. F.; TORRES, T. Z.; AMARAL, S. F. do. Bibliotecas digitais e dispositivos móveis: acesso a novos espaços de aprendizagem. 2011. Disponível em: https://www.alice.cnptia.embrapa.br/alice/bitstream/doc/898118/1/Bibliotecasdigitais.pdf Acesso em: 16 dez. 2016.

TELECO. Estatísticas de celulares no Brasil. 2016. Disponível em: http://www.teleco.com.br/ncel.asp Acesso em: 06 dez. 2016.

VOELCKER, M. Uso de tecnologias da informação e comunicação em bibliotecas públicas no Brasil. Fundação Pensamento Digital, 2013. Disponível em:

http://ticsbps.weebly.com/uploads/2/1/0/4/21045142/_relatorio_de_pesquisa_ptg.pdf Acesso em: 16 dez. 2016. 


\title{
INNOVATION IN LIBRARIES: EXPERIENCE REPORT ON THE CREATION OF THE APPLICATION VESTBOOK SC
}

\begin{abstract}
The work presents a report of experience on opportunities for the use of information and communication technologies (ICT), in particular smartphone in public libraries. With the development and advancement of technologies, communication between people has become more rapid and efficient, which facilitates the dissemination of information. The creation of an application with the objective of gathering in one device, information on the literary works required in the main vestibular of the universities of Santa Catarina. The use of the application is beneficial to users of public libraries, facilitating access to information from books to students.
\end{abstract}

Keywords: Information and communication technologies. Mobile apps. Public Library. Experience reporting.

\section{GUILHERME MARTINS}

Bibliotecário da Rede Municipal de Bibliotecas da Prefeitura Municipal de Florianópolis; Mestrando em Gestão de Unidades de Informação na Universidade do Estado de Santa Catarina (UDESC). E-mail: gm.biblio@gmail.com

\section{HELEN MORO DE LUCA}

Bibliotecária na Biblioteca Pública de Santa Catarina; Mestranda em Gestão de Unidades de Informação na Universidade do Estado de Santa Catarina (UDESC). E-mail: helen.mdeluca@ gmail.com

\section{JANAÍNA DOS SANTOS SCHWEITZER}

Bibliotecária na Biblioteca Pública de Santa Catarina; Mestranda em Gestão de Unidades de Informação na Universidade do Estado de Santa Catarina (UDESC). E-mail: janaedino@ gmail.com

\section{JORDAN PAULESKY JULIANI}

Professor no Mestrado Profissional de Gestão de Unidades de Informação do Programa de Pós-Graduação em Gestão da Informação da Universidade do Estado de Santa Catarina (PPGINFO). Doutor em Engenharia e Gestão do Conhecimento - Universidade Federal de Santa Catarina (UFSC). E-mail: jordan@webpack.com.br

\section{DIVINO IGNÁCIO RIBEIRO JUNIOR}

Professor no Mestrado Profissional de Gestão de Unidades de Informação do Programa de Pós-Graduação em Gestão da Informação da Universidade do Estado de Santa Catarina (PPGINFO). Doutor em Engenharia e Gestão do Conhecimento - Universidade Federal de Santa Catarina (UFSC). E-mail: divinoirj@gmail.com

RECEBIDO EM: 22-03-2017

ACEITO EM: 23-11-2017 